\title{
Evolution of Structure, Microstructure, Electrical and Magnetic Properties of Nickel Oxide (NiO) with Transition Metal ion Doping
}

\author{
P. Mallick ${ }^{1, *}$, N. C. Mishra ${ }^{2}$ \\ ${ }^{1}$ Department of Physics, North Orissa University, Baripada, 757003, India \\ ${ }^{2}$ Department of Physics, Utkal University, Bhubaneswar, 751004, India
}

\begin{abstract}
We present a brief review on the evolution of structure, microstructure, electrical and magnetic properties of $\mathrm{NiO}$ with transition metal (TM) doping. The fcc structure of $\mathrm{NiO}$ is not affected with $\mathrm{TM}$ doping whereas the some of the $\mathrm{TM}$ ion influences the microstructure. The antiferromagnetic property of $\mathrm{NiO}$ is strongly modified with some of the $\mathrm{TM}$ $(\mathrm{Fe}, \mathrm{Mn}, \mathrm{V})$ doping and the same is not much affected with some other $\mathrm{TM}(\mathrm{Co}, \mathrm{Cr}, \mathrm{Zn}$ and $\mathrm{Cu})$ doping. Not only the dopants but also the form of the material decides the magnetic order in the host matrix. Powder NiO exhibits room temperature ferromagnetism with $\mathrm{Fe}$ doping, superparamagnetism with $\mathrm{Mn}$ doping. NiO thin films on the other hand exhibit ferromagnetism with $\mathrm{Fe}, \mathrm{Mn}$ and $\mathrm{V}$ doping. The ferromagnetic ordering in these cases was improved with Li co-doping. The increased ferromagnetism in these cases may be due to increase of hole concentration due to Li doping. Giant dielectric response has been observed for $(\mathrm{Li}, \mathrm{Fe})$ and $(\mathrm{Li}, \mathrm{V})$ doped $\mathrm{NiO}$ ceramics.
\end{abstract}

Keywords Diluted Magnetic Semiconductors; Doping; Transition Metal Oxide; Nio

\section{Introduction}

The different properties that a material exhibits can undergo extensive modification on doping with foreign elements. There are situations where the host matrix only acts as a vehicle, but its property is solely dictated by the dopants. The induction of extrinsic conductivity (either $\mathrm{p}$ or $\mathrm{n}$ type) in silicon, germanium semiconductors on trivalent or pentavalent ion doping, emergence of high $\mathrm{T}_{\mathrm{C}}$ superconductivity or colossal magneto-resistivity on doping of cuprateperovskites and manganites, tuning of band gap in materials for applications in solar cell technology are a few out of a large varieties of phenomena and applications that emerge on doping. Though many elements in the periodic table can be doped in a host matrix depending upon the chemical compatibility, the transition metal elements have specific advantages when used as dopant.

$\mathrm{NiO}$ has been considered as a promising functional material for varieties of applications as smart windows, spin valves giant magneto resistance (GMR) sensor, solar cells,p-type transparent conducting electrodes, gas sensors, high permittivity dielectric material and electrochromic material for displays etc. TM doped $\mathrm{NiO}$ samples have been

* Corresponding author:

pravanjan_phy@yahoo.co.in (P. Mallick)

Published online at http://journal.sapub.org/materials

Copyright (C) 2012 Scientific \& Academic Publishing. All Rights Reserved studied mainly for their dielectric and magnetic properties. However, the major focus has been confined to the evolution of magnetic property in $\mathrm{NiO}$ with $\mathrm{TM}$ doping.

High-permittivity dielectric materials with good thermal stability have been played a significant role in microelectronics. Giant dielectric response has been observed for $(\mathrm{Li}$, $\mathrm{Fe})$ and $(\mathrm{Li}, \mathrm{V})$ doped $\mathrm{NiO}[1,2]$. The effects of transition metal like $\mathrm{Fe}, \mathrm{Co}, \mathrm{Mn}$ etc. doping can drive a non-magnetic semiconductor into a semiconductor with ferromagnetism. This has led to the emergence of a new field of research, the diluted magnetic semiconductors (DMS). DMS has charge and spin degrees of freedom in a single substance to realize a new class of spintronic devices. The potential advantages of spintronic devices will be higher speed, greater efficiency, and better stability, in addition to the low energy required to flip a spin[3]. For practical applications, the DMS materials need to exhibit high Curie temperature $(>300 \mathrm{~K}$ ) with intrinsic ferromagnetism rather than one due to the presence of secondary phases.It is anticipated that if one can introduce room temperature ferromagnetism in cubic systems, it will facilitate the integration of spintronic devices with advanced silicon based microelectronic devices[4]. Dietlet al.[5] had predicted that the curie temperature of p-type DMS can be well above that of n-type DMS. NiO exhibits fcc structure. It is a prototype p-type transparent conducting oxide[6,7] due to vacancy at $\mathrm{Ni}^{2+}$ sites $[8,9]$. $\mathrm{NiO}$ as such is a transition metal oxide. Doping of other transition metal elements at Ni site modifies the magnetic, electrical, optical and to some extent 
structural properties, and opens up the possibility of exploiting this material for DMS functionality. Here, we present a brief review on the evolution of structure, microstructure, electrical and magnetic properties of $\mathrm{NiO}$, on doping with different TM elements.

\section{Evolution of Structure and Microstructure of Nio with Transition Metal Doping}

Bulk NiO exhibits cubic (fcc) structure with a slight rhombohedral distortion below the Neel temperature, $\mathrm{T}_{\mathrm{N}}$ $(\sim 523 \mathrm{~K})$. This distortion is believed to be a consequence of the confinement of ferromagnetically ordered spins within the (111) plane[10]. Due to this spin structure, the exchange coupling to the nearest neighbours within the ferromagnetic planes is slightly larger than that to the nearest neighbours out of these planes, with antiferromagntic coupling between adjacent planes. This exchange striction manifests itself in $\mathrm{NiO}$ not being perfectly cubic but having a small contraction of the distance between the ferromagnetically ordered planes below $\mathrm{T}_{\mathrm{N}}[11]$. However, the difference in plane spacing is only about $0.1 \%$ at $300 \mathrm{~K}[11]$ and this deviation from cubic symmetry is in general ignored[12]. The fcc structure of $\mathrm{NiO}$ is retained with different TM doping such as $\mathrm{Fe}, \mathrm{Co}, \mathrm{Mn}$ by different concentrations within the solubility limit[13-16]. However the microstructure of the host NiO matrix is influenced considerably by the dopant ions.

In general TM monoxides exhibit either cation or anion vacancies. The former category includes $\mathrm{ZnO}, \mathrm{CdO}, \mathrm{VO}$, etc., while the latter category includes $\mathrm{NiO}, \mathrm{FeO}, \mathrm{CoO}$ and $\mathrm{MnO}$. In the latter category of transition metal monoxide (TMO), the formation of microstructural defects, such as metal vacancies and interstitial oxygen has been seen. Among these TMOs, NiO has been shown to exhibit least amount of non-stoichiometry in its bunsenite form, $\mathrm{Ni}_{1-\delta} \mathrm{O}(\delta<1 \times$ $\left.10^{-3}\right)[17]$. The values of $\delta$ for $\mathrm{Fe}_{1-\delta} \mathrm{O}, \mathrm{Mn}_{1-\delta} \mathrm{O}$ and $\mathrm{Co}_{1-\delta} \mathrm{O}$ are 0.05-0.15, 0.001-0.15 and 0.001-0.05 respectively[17]. Due to the difference in non-stoichiometry, any of the ions like Fe, $\mathrm{Co}, \mathrm{Mn}$ if used as dopant, is expected to govern the defect structure of $\mathrm{NiO}$. The $\mathrm{Fe}_{1-\delta} \mathrm{O}$ in its wustite state is well known to produce the defect clusters, consisting of cation vacancies and iron interstitials[18-20]. The basic unit of these clusters, the so-called (4:1)-clusters, consists of four cation vacancies, tetrahedrally coordinating a trivalently charged iron interstitial ion. This gives rise to the generation of 5 holes around the defect structure. As in wustite, the 4:1 clusters can occur in the bunseniteNiO due to $\mathrm{Fe}$ doping. In this case a $\mathrm{Fe}^{3+}$ ion occupying interstitial site is coordinated to $4 \mathrm{Ni}$ vacancies. Such a defect structure in $\mathrm{Fe}$ doped $\mathrm{NiO}$ was predicated by theoretical studies[17] and indicated by neutron scattering experiments[21]. Similar is the situation with $\mathrm{Mn}$ and Co doping, where the defect structure in $\mathrm{MnO}$ and $\mathrm{CoO}$ is expected to be reflected in the structure of $\mathrm{NiO}$ if doped by $\mathrm{Mn}$ or Co. The available literature on TM doped $\mathrm{NiO}$ indicates that only a few studies have been undertaken on the bulk samples[22-24]. Most of the studies on TM doped $\mathrm{NiO}$ are confined to nanostructure rather than bulk. In some cases, though attempts have been made to synthesize bulk phase samples, the segregation of secondary phases prevails and inclusion of nanoparticles of dopants in the host matrix occurs.

The particle size of $\mathrm{NiO}$ increases on increasing annealing temperature[25,26] and annealing time[25]. Interestingly, the particle size of $\mathrm{NiO}$ has been shown to decrease with increasing TM doping concentration[13,15,27]. Similar type of observation has been reported for Mn doped ( $\mathrm{ZnAs}) \mathrm{O}$ also, where $\mathrm{Mn}$ was shown to be a potential catalyst for nano dot formation[28]. The exact role of TM ions in reducing the particle size is still elusive.

$\mathrm{Li}$ is not a transition metal. However Li doping has been shown to influence the non-stoichiometry of NiO. Due to its valence state being different from that of $\mathrm{Ni}$, its co-doping with another TM ion into $\mathrm{NiO}$ is expected to affect the defect structure as well as the physical properties of $\mathrm{NiO}$. The $\mathrm{Ni}_{0.98-\mathrm{x}} \mathrm{Fe}_{0.02} \mathrm{Li}_{\mathrm{x}} \mathrm{O}$ samples show improved texturing along $<111>$ with increasing Li concentration[29]. The texture evolution of $\mathrm{NiO}$ has been shown to be governed by crystallinity and grain size[30]. Increasing substrate temperature during the film growth by RF sputtering results into increased grain size and leads to suppression of texture along $<111>$ and the evolution of the same along $<200>$. Therefore the enhanced texture along $<111>$ indicates that Li doping suppresses the crystallinity and hence grain size. Like ( $\mathrm{Li}, \mathrm{Fe})$ doped $\mathrm{NiO}$ case, $1 \mathrm{wt} \%$ Co doped $\mathrm{NiO}$ also showed the texturing along $<111>[31]$, which may be due to the suppression of grain size. On the contrary, the grain size was found to remain unaffected with Co concentration in $\mathrm{Co}, \mathrm{Li}$ co-doped $\mathrm{NiO}$ [32]. The grain size also remains unaffected in low doping concentration of $\mathrm{Mn}$ in $\mathrm{NiO}$ and the same decreased at higher Mn concentration[16].

\section{Evolution of Electrical Properties of NiO with Transition metal Doping}

The electrical conductivity of many metal oxide semiconductors is extensively influenced by impurity doping. The classical example is the dramatic increase in electrical conductivity of silicon and germanium with parts per million (ppm) level of impurity. As such $\mathrm{NiO}$ is a hole doped p-type semiconductor. The electrical conductivity of undopedNiO has a strong dependence on the formation of microstructural defects, such as nickel vacancies and interstitial oxygen in $\mathrm{NiO}$ crystallites[33]. With proper thermal treatment, it becomes slightly non-stoichiometric, acquiring an excess of oxygen, which is compensated by the oxidation of some $\mathrm{Ni}^{2+}$ to $\mathrm{Ni}^{3+}$. In the ground state, the extra charge of $\mathrm{Ni}^{3+}$ is trapped close to the $\mathrm{Ni}$ vacancy[34,35] and can move only by an activated hopping process similar to that exhibited by ionic diffusion. Therefore, this kind of compound is generally designated as a hopping semiconductor[36]. The non-stoichiometry and hence p-type conductivity in $\mathrm{NiO}$ can 
be further enhanced by doping of aliovalent metal ions like $\mathrm{Li}$ at $\mathrm{Ni}$ site[13,37]. Intensive investigations have been conducted in doped $\mathrm{NiO}$ for its great theoretical and technological importance due to the special electrical behaviours and related spin dynamics[9,38].

$\mathrm{NiO}$ has also been shown to evolve with different properties like high dielectric permittivity[1,2,39,40], thermoelectric behaviour[41,52], ferromagnetism[13,24-27,29,43] etc. on doping. However only a few studies have been undertaken on the electrical properties of TM doped NiO.

The activation energy and hence the frequency dependent electrical conductivity of $\mathrm{NiO}$ have been shown to sensitively depend on Fe doping at very low concentrations. Fe doping $(0.5$ at. $\%)$ leads to increase of the activation energy of $\mathrm{NiO}$ (from $\sim 0.51 \mathrm{eV}$ to $\sim 0.85 \mathrm{eV}$ ). Further increasing $\mathrm{Fe}$ concentration has a little influence on the activation energy, which probably is due to the solubility restrictions[27]. Like $\mathrm{Fe}$ doping case, the activation energy for the nanocrystallineMn doped $\mathrm{NiO}$ was found to be greater than that of undopedNiO[44]. Co-doping of $\mathrm{NiO}$ with TM ions and $\mathrm{Li}^{+}$ions have been attempted to induce changes in both magnetic and electrical properties, which can induce DMS behaviour as discussed later. As such the replacement of $\mathrm{Ni}^{2+}$ by $\mathrm{Li}^{+}$increases hole carrier concentration[ $[45,46]$. The occurrence of higher conductivity has been reported for $\mathrm{Ni}_{0.98-x} \mathrm{Fe}_{0.02} \mathrm{Li}_{\mathrm{x}} \mathrm{O}$ samples with increasing Li concentration[29]. The increased conductivity with Li concentration may be due to the increase of the hole concentration and the decrease of the activation energy, as observed in the $\mathrm{Li}_{x} \mathrm{Ni}_{1-x} \mathrm{O}$ system[46].

$\mathrm{NiO}$ in recent years has been considered as an important dielectric material due to its high-permittivity when doped with different elements. Among the different element doped $\mathrm{NiO},(\mathrm{Li}, \mathrm{Fe})$ and $(\mathrm{Li}, \mathrm{V})$ doped $\mathrm{NiO}$ have shown to exhibit giant dielectric response[1,2]. The observation of high dielectric constant in doped $\mathrm{NiO}$ is attributed mainly to a grain boundary barrier layer capacitance[9,47,48], which can arise due to the formation of core/shell structure with conductive grain as core and resistive boundary as shell[1,2].

\section{Evolution of Magnetic Properties of Nio with Transition Metal Doping}

$\mathrm{NiO}$ in its bulk form shows antiferromagnetic behaviour. The magnetic structure of $\mathrm{NiO}$ consists of ferromagnetic sheets of $\mathrm{Ni}^{2+}$ parallel to the (111) plane with opposite spin directions in neighboring sheets. Magnetic properties of $\mathrm{NiO}$, in addition to depending on TM ion doping, also sensitively depends on the size of the particles in nanoscale of the particle size. We thus present a brief discussion on particle size effect before going over to TM doping effect on magnetic properties of $\mathrm{NiO}$.

When the dimension is reduced to nanoscale, the antiferromagnetic material like $\mathrm{NiO}$ is shown to exhibit different magnetic properties like ferromagnetism[49] (for particles of size, $\mathrm{D} \leq 24 \mathrm{~nm})$, superparamagnetism $(\mathrm{D} \leq 31.5 \mathrm{~nm})$ [50], spin glass behavior ( $\mathrm{D} \leq 10 \mathrm{~nm})[51,52]$ and even core-shell like structure $(4 \leq \mathrm{D} \leq 22 \mathrm{~nm})[53]$, where the core of $\mathrm{NiO}$ nanoparticle behaves like a ferrimagnet and the shell contains randomly oriented spins with low co-ordination. Thus depending upon the particle size, different anomalous magnetic properties emerge at the expense of antiferromagnetic property of the host $\mathrm{NiO}$. $\mathrm{NiO}$ nanoparticles are shown to exhibit finite size effect, where 8-, 6-, or 4-sublattice spin configurations arise due to the reduced coordination of surface spins leading to anomalous magnetic properties like large moments and coercivity, and loop shifts[50]. These anomalous properties however emerge only when the particle size is less than a critical size ( 31.5 $\mathrm{nm})[50]$.

The effect of TM iondoping on the magnetic properties of $\mathrm{NiO}$ is still not explored well. In recent years, TM ions such as $\mathrm{Fe}, \mathrm{Co}, \mathrm{Mn}$ etc. have been used as dopant for $\mathrm{NiO}$. Fe doping in $\mathrm{NiO}$ leads to ferromagnetism in both nanoparticle and thin film form whereas $\mathrm{Mn}$ and $\mathrm{V}$ doped $\mathrm{NiO}$ exhibits ferromagnetism in thin film form. The TM iondoped materials which exhibit ferromagnetism is generally regarded as Diluted magnetic semiconductors (DMS) and are important class of materials due to their potential applications for spintronic devices[54,55]. The studies on the evolution of ferromagnetism in $\mathrm{TM}$ doped $\mathrm{NiO}$ are mostly confined either to nanoparticle powders or to thin films. Attempts have been made to synthesize bulk Fe doped $\mathrm{NiO}$ either by solid state reaction method[24] or by high temperature annealing of nanoparticles $[25,26]$. These studies however indicated phase segregation and precipitation of secondary impurity phase of doped ions, questioning the intrinsic nature of DMS. On the contrary, the Co doped NiO did not show any impurity phase. It also did not show any drastic change in magnetic property unlike Fe doping case. Though $\mathrm{Li}$ is not a TM ion, its doping into $\mathrm{NiO}$ has been shown to considerably influence the electrical as well as the magnetic properties[56-58]. We therefore discuss literatures on the evolution of magnetic properties on TM doping as well as on ( $\mathrm{Li}, \mathrm{TM})$ doping in $\mathrm{NiO}$.

\subsection{Fe and ( $\mathrm{Li}, \mathrm{Fe})$ doped $\mathrm{NiO}$}

Ferromagnetism has been shown to evolve in $\mathrm{NiO}$ at room temperature on doping with 2 at.\% $\mathrm{Fe}[13,15,26,27,43]$. However the origin of the occurrence of ferromagnetism is still not clear. In order to get information about the origin of ferromagnetism in $\mathrm{Fe}$ doped NiO,Douvalis et al.[25] prepared $\mathrm{Ni}_{0.98} \mathrm{Fe}_{0.02} \mathrm{O}$ by chemical method and heated this precursor in air at temperatures between 673 and $873 \mathrm{~K}$, for 1 to $25 \mathrm{~h}$. Their magnetization measurements show that samples heated both at 673 and $873 \mathrm{~K}$ exhibit room-temperature ferromagnetism. However their Mossbauer spectroscopy results indicate that this ferromagnetism is related to $\mathrm{Ni}^{57} \mathrm{Fe}_{2} \mathrm{O}_{4}$ ferrimagnetic impurities for the samples heated at $873 \mathrm{~K}$ and to finite-size effects for the samples heated at 673 $\mathrm{K}$. This observation thus indicated that ferromagnetism in $\mathrm{Fe}$ doped $\mathrm{NiO}$ is not due to Fe induced DMS effect as was ini- 
tially presumed by many[13,27], but due to second phase precipitation. Thermogravimetric and magnetic study of polycrystalline $\mathrm{Fe}$ doped $\mathrm{NiO}$ samples prepared by solid state reaction method by Raja et al.[24] also indicated that the observed ferromagnetism in these samples is due to second phase $\left(\mathrm{NiFe}_{2} \mathrm{O}_{4}\right)$ precipitation like that observed by Douvalis et al.[25].

Li doping into $\mathrm{NiO}$ leads to the generation hole as charge carriers. Li co-doping was introduced into the TM doped $\mathrm{NiO}$ with an aim to achieve strong carrier mediated ferromagnetism at room temperature. The evolution of magnetic ordering in the $\mathrm{Fe}$, $\mathrm{Li}$ co-doped $\mathrm{NiO}$ showed an opposite behaviour in polycrystalline powder samples than in thin films with increasing $\mathrm{Li}$ concentration. The powder $\mathrm{Ni}_{0.98-\mathrm{x}} \mathrm{Fe}_{0.02} \mathrm{Li}_{\mathrm{x}} \mathrm{O}$ samples[37] did not show the enhanced ferromagnetic properties unlike the $\mathrm{Ni}_{0.98-\mathrm{x}} \mathrm{Fe}_{0.02} \mathrm{Li}_{\mathrm{x}} \mathrm{O}$ thin films[29,59].

In polycrystalline $\mathrm{Fe}, \mathrm{Li}$ co-doped $\mathrm{NiO}$ powder samples, the ferromagnetic transition temperature was shown to decrease with increasing Li concentration. In this case, the random substitution of $\mathrm{Li}$ in $\mathrm{Fe}$ doped $\mathrm{NiO}$ leads to the formation of ferromagnetic phases locally which is embedded inside the antiferromagnetic host $\mathrm{NiO}$. The coexistence of ferromagnetic and antiferromagnetic phases lead to spin glass type behavior in $\mathrm{NiO}$ system as a result of which ferromagnetic transition temperature decreased[37].

In case of $\mathrm{Fe}$, $\mathrm{Li}$ co-doped $\mathrm{NiO}$ thin films, the room temperature ferromagnetic ordering was shown to improve with increasing Li concentration[59]. Since holes are generated on $\mathrm{Li}$ doping in $\mathrm{NiO}$, the density of holes increases with increasing Li concentration. More hole carriers are expected to enhance the ferromagnetic coupling interaction between the hole carriers and the $\mathrm{Fe} 3 d$ spins, thus making ferromagnetic coupling interaction more effective as was reported for $\mathrm{Fe}$, Li co-doped thin films[29,59]. Similar phenomena have also been observed in the $\mathrm{Li}$, Co co-doped $\mathrm{ZnO}$ and $\mathrm{Cu}$, Fe co-doped $\mathrm{ZnO}$ thin films[60,61].

\section{2. $\mathrm{Co}$ and ( $\mathrm{Li}, \mathrm{Co})$ doped $\mathrm{NiO}$}

The magnetic structure of the solid solutions of $\mathrm{Ni}_{1-\mathrm{x}} \mathrm{Co}_{\mathrm{x}} \mathrm{O}$ as a function of composition and temperature has been studied by neutron diffraction technique[23]. As indicated from this study, the antiferromagnetic ordering persists in Co doped $\mathrm{NiO}$. The $\mathrm{T}_{\mathrm{N}}$ decreased linearly with increasing Co concentration in $\mathrm{NiO}[62]$. Since the $\mathrm{T}_{\mathrm{N}}$ of $\mathrm{CoO}$ and $\mathrm{NiO}$ are $\sim 287 \mathrm{~K}$ and $523 \mathrm{~K}$ respectively, the replacement of Co with $\mathrm{Ni}$ thus results into the linear decrease of $\mathrm{T}_{\mathrm{N}}$ with increasing Co concentration in Co doped $\mathrm{NiO}$ as observed.

$\mathrm{Li}$ co-doping with $\mathrm{Co}$ inNiO thin films indicated ferromagnetic (FM) like ordering occurring at low temperature due to hole mediation as discussed earlier. $\mathrm{Co}$ and $\mathrm{Li}$ co-doped $\mathrm{NiO}$ nanostructured films grown of $\mathrm{MgO}$ (100) substrate for example exhibit FM like ordering at low temperatures $(5 \mathrm{~K})$, while the system is slightly paramagnetic at room temperature[32]. Antiferromagntism still dominates at room temperature. To delineate the effect of magnetic ion from the hole concentration, these authors studied the evo- lution of magnetization with Co concentration keeping the $\mathrm{Li}$ concentration fixed. The samples did not show any dramatic change in the magnetic behaviour with different Co concentration. Since the density of hole is not expected to vary with different Co concentration, it did not influence the antiferromagnetic structure of $\mathrm{NiO}$ much. The FM-like ordering as seen at low-temperature has been attributed to the manifestation of localized nature of the $\mathrm{Li}$ induced carrier and the low free carrier density[32].

\subsection{Mn and (Li, Mn) doped $\mathrm{NiO}$}

The evolution of magnetization in $\mathrm{Mn}$ doped $\mathrm{NiO}$ showed different behaviour in polycrystalline power samples than in thin film from. With increasing Mn doping concentration polycrystalline $\mathrm{NiO}$ powder shows superparamegntism at the expense of antiferromagnetism. The antiferro to superparamagnetic transition on $\mathrm{Mn}$ doping in $\mathrm{NiO}$ is explained on the basis of Mn occupying Ni site and breaking the translational symmetry of the parent antiferromagnetic correlation[16].

$\mathrm{Mn}$ doped $\mathrm{NiO}$ thin films are shown to exhibit room temperature ferromagnetic behaviour. The ferromagnetic properties of the $\mathrm{Mn}$ doped $\mathrm{NiO}$ is also shown to increase by $\mathrm{Li}$ co-doping like $\mathrm{Fe}$ doping case. The occurrence of ferromagnetism in $\mathrm{Mn}$ doped $\mathrm{NiO}$ is ascribed to intrinsic in nature. The enhancement of ferromagnetism in $(\mathrm{Li}, \mathrm{Mn})$ doped $\mathrm{NiO}$ is due to double exchange coupling effects via Li-induced holes[63].

\subsection{Other TM ( V, Cr, Cu, Zn) doped NiO}

Recently, the effect of $\mathrm{V}, \mathrm{Cr}, \mathrm{Cu}$ and $\mathrm{Zn}$ doping and their co-doping with $\mathrm{Li}$ on the magnetic properties of $\mathrm{NiO}$ thin films have been studied[63]. Magnetization measurements in these cases reveal that $\mathrm{V}$ doped $\mathrm{NiO}$ thin films show room-temperature ferromagnetic behaviours and the same is shown to increase with $\mathrm{Li}$ co-doping like $\mathrm{Fe}$ and $\mathrm{Mn}$ doped $\mathrm{NiO}$ thin films. NiO thin films show antiferromagnetic behaviour with nearly zeromagnetic moments for $\mathrm{Cr}, \mathrm{Zn}$, and $\mathrm{Cu}$ doping. The antiferromagnetic behaviour of these samples also does not change much with Li co-doping even up to $15 \%$ of the Li concentration[63].

\section{Conclusions}

The evolution of different properties of $\mathrm{NiO}$ on TM doping is reviewed. The structure of $\mathrm{NiO}$ is not being affected with TM doping whereas the microstructure is influenced by some of the TM ions. Giant dielectric response has been observed for $(\mathrm{Li}, \mathrm{Fe})$ and $(\mathrm{Li}, \mathrm{V})$ doped NiOceramics. Powder $\mathrm{NiO}$ exhibits room temperature ferromagnetism with Fe doping, superparamagnetism with $\mathrm{Mn}$ doping. Antiferromagnetic property of the host $\mathrm{NiO}$ either in powder form or in thin film form is not influenced with Co doping. $\mathrm{NiO}$ thin films on the other hand exhibit ferromagnetism with $\mathrm{Fe}, \mathrm{Mn}$ and $\mathrm{V}$ doping. The ferromagnetic ordering in these cases improve with $\mathrm{Li}$ co-doping. The increased 
ferromagnetism in these cases may be due to increase of hole concentration due to Li doping.

\section{REFERENCES}

[1] Pongha S, Thongbai P, Yamwong T, Maensiri S (2009). Giant dielectric response and polarization relaxation mechanism in (Li,V)-doped NiO ceramics. Scripta Mater., 60: 870-873.

[2] Thongbai P, Yamwong T, Maensiri S (2009). Electrical responses in high permittivity dielectric ( $\mathrm{Li}, \mathrm{Fe})$-doped $\mathrm{NiO}$ ceramics. Appl. Phys. Lett., 94: 152905-3.

[3] Das Sarma S, (2001). A new class of device based on electron spin, rather than on charge, may yield the next generation of microelectronics. American Scientist, 89: 516-523.

[4] Tiwari A, Bhosle VM, Ramachandran S, Sudhakar N, Narayan J, Budak S, Gupta A. (2006). Ferromagnetism in Co doped $\mathrm{CeO}_{2}$ : Observation of a giant magnetic moment with a high Curie temperature. Appl. Phys. Lett., 88:142511-3.

[5] Dietl T, Ohno H, Matsukura F, Cibert J, Ferrand D (2000). Zener Model Description of Ferromagnetism in Zinc-Blende Magnetic Semiconductors. Science,287: 1019-1022.

[6] Sato H, Minami T, Takata S, Yamada T (1993). Transparent conducting p-type $\mathrm{NiO}$ thin films prepared by magnetron sputtering. Thin Solid Films, 236: 27-31.

[7] Joshi US, Matsumoto Y, Itaka K, Sumiya M, Koinuma H (2006). Combinatorial synthesis of Li-doped $\mathrm{NiO}$ thin films and their transparent conducting properties. Appl. Surf. Sci., 252: 2524-2528.

[8] Bidault O, Maglione M, Actis M, Kchikech M (1995). Polaronic relaxation in perovskites. Phys. Rev. B, 52: 4191-4197.

[9] Wu J, Nan C-W, Lin Y, Deng Y(2002). Giant dielectric permittivity observed in $\mathrm{Li}$ and $\mathrm{Ti}$ doped NiO. Phys. Rev. Lett., 89: 217601-217604.

[10] Hutchings MT, Samuelsen EJ (1972). Measurement of spin-wave dispersion in $\mathrm{NiO}$ by inelastic neutron scattering and its relation to magnetic properties. Phys. Rev. B, 6: 3447-3461.

[11] Bartel LC, Morosin B (1971). Exchange Striction in NiO. Phys. Rev. B, 3: 1039-1043.

[12] Bahl CRH, Hansen MF, Pedersen T, Saadi S, Nielsen KH, Lebech B, Mørup S (2006). The magnetic moment of NiO nanoparticles determined by M"ossbauer spectroscopy. J. Phys.: Condens. Matter, 18: 4161-4175.

[13] Wang J, Cai J, Lin Y-H, Nan C-W (2005).Room-temperature ferromagnetism observed in Fe-doped NiO. Appl. Phys. Lett., 87: 202501-3.

[14] Mallick P, Rath C, Biswal R, Banerjee A, Mishra NC (2008). Effect of $\mathrm{Fe}$ and $\mathrm{Co}$ doping on the structural and magnetic properties of NiO. Indian J. Cryo. 33: 52.

[15] Mallick P, Rath C, Biswal R, Mishra NC (2009). Structural and magnetic properties of Fe doped NiO. Indian J. Phys., 83: 517-523.

[16] Mallick P, Rath C, Rath A, Banerjee A, Mishra NC (2010).
Antiferro to superparamagnetic transition on Mn doping in NiO. Solid State Commun., 150: 1342-1345.

[17] Grimes RW, Anderson AB, Heuer AH (1987). Interaction of dopant cations with 4:1 defect clusters in non-stoichiometric $3 d$ transition metal monoxides: a theoretical study. J. Phys. Chem. Solids, 48: 45-50.

[18] Koch F, Cohen JB (1969). The defect structure of $\mathrm{Fe}_{1-x} \mathrm{O}$. ActaCryst. B, 25: 275-287.

[19] Anderson AB, Grimes RW, Heuer AH (1984). Defect clusters in wustite, $\mathrm{Fe}_{1-x} \mathrm{O}$. J. Solid State Chem., 55: 353-361.

[20] Schweika W, Hoser A, Martin M, Carlsson AE (1995). Defect structure of ferrous oxide $\mathrm{Fe}_{1-x} \mathrm{O}$. Phys. Rev. B, 51: 15771-15788.

[21] Hoser A, Martin M, Schweika W, Carlsson AE, Chaudron R, Pyka N (1994). Diffuse neutron scattering of iron-doped nickel oxide. Solid State Ionics, 72: 72-75.

[22] Нaаß F, Buhrmester T, Martin M (2001). Quantitative elaboration of the defect structure of iron doped nickel oxide $\left(\mathrm{Ni}_{0.955} \mathrm{Fe}_{0.045}\right)_{1-} \delta$ O by in situ X-ray absorption spectroscopy. Phys. Chem. Chem. Phys., 3: 4806-4810.

[23] Battle PD, Cheetham AK, Gehring GA (1979). A neutron diffraction study of the structure of the antiferromagnet $\mathrm{Co}_{\mathrm{p}} \mathrm{Ni}_{1-\mathrm{p}} \mathrm{O}$. J. Appl. Phys., 50: 7578-7580.

[24] Raja SP, Venkateswaran C (2009). Investigation of magnetic behaviour of $\mathrm{Ni}-\mathrm{Fe}-\mathrm{O}$ prepared by the solid state method. J. Phys. D: Appl. Phys., 42: 145001-145006.

[25] Douvalis AP, Jankovic L, Bakas T (2007). The origin of ferromagnetism in ${ }^{57} \mathrm{Fe}$-doped NiO. J. Phys.: Condens. Matter, 19: 436203-436227.

[26] He JH, Yuan SL, Yin YS, Tian ZM, Li P, Wang YQ, Liu KL, Wang $\mathrm{CH}$ (2008). Exchange bias and the origin of room-temperature ferromagnetism in Fe-doped $\mathrm{NiO}$ bulk samples. J. Appl. Phys., 103:023906-4.

[27] Lin Y-H, Wang J, Cai J, Ying M, Zhao R, Li M, Nan C-W (2006). Ferromagnetism and electrical transport in Fe-doped NiO. Phys. Rev. B, 73: 193308-4.

[28] Lord K, Williams TM, Hunter D, Zhang K, Dadson J, Pradhan AK (2006). Effects of As and Mn doping on microstructure and electrical conduction in $\mathrm{ZnO}$ films. Appl. Phys. Lett., 88: 262105-3.

[29] Lin Y-H, Zhao R, Nan C-W, Ying M, Kobayashi M, Ooki Y, Fujimori A (2006). Enhancement of ferromagnetic properties of NiO:Fe thin film by Li doping. Appl. Phys. Lett., 89: 202501-3.

[30] Chen HL, Lu YM, Hwang WS (2005). Characterization of sputtered NiO thin films. Surf. Coat. Technol., 198: 138-142.

[31] Zheng Z, Huang L, Zhou Y, Hu X, Ni X (2009). Large-scale synthesis of mesoporousCoO-doped $\mathrm{NiO}$ hexagonal nanoplatelets with improved electrochemical performance. Solid State Sci., 11:1439-1443.

[32] Joshi US, Itaka K, Matsumoto Y, Koinuma H (2009). Combinatorial fabrication and magnetic properties of homoepitaxial $\mathrm{Co}$ and $\mathrm{Li}$ co-doped $\mathrm{NiO}$ thin-film nanostructures. J. Magn. Magn. Mater., 321: 3595-3599.

[33] Antolini E (1992). Sintering of $\mathrm{Li}_{x} \mathrm{Ni}_{1-x} \mathrm{O}$ solid solutions at 
$1200^{\circ}$ C. J. Mater Sci., 27 : 3335-3340.

[34] Keem JE, Honig JM, van Zandt LL (1978). Localized charge carrier transport in pure single crystals of NiO. Philos. Mag. B, 37: $537-543$.

[35] Cox PA (1998). The electronic structure and chemistry of solids, Oxford Science Publications, Oxford, Chapter 5.3.

[36] Tuller HL (1981). In: O.T. Sørensen (ed) Nonstoichiometric oxides, Academic Press, San Diego, Chapter 6.

[37] Manna S, De SK (2009). Magnetic properties of Li and Fe co-dopedNiO.Solid State Commun., 149: 297-300.

[38] Lin Y, Jiang L, Zhag R, Nan C-W (2005). High-permittivity core/shell stucturedNiO-based ceramics and their dielectric response mechanism. Phys. Rev. B, 72: 014103-014108.

[39] MannaS, DuttaK, DeSK(2008). High dielectric permittivity observed in Na and Al doped NiO. J. Phys. D: Appl. Phys.,41:155416-155421.

[40] Tangwancharoen S, Thongbai P, Yamwong T, Maensiri S (2009). Dielectric and electrical properties of giant dielectric ( $\mathrm{Li}, \mathrm{Al}$ )-doped $\mathrm{NiO}$ ceramics. Mater. Chem. Phys., 115: 585-589.

[41] ShinW, Murayama N (1999). Li-Doped Nickel Oxide as a Thermoelectric Material.Jpn. J. Appl. Phys., 38: L1336-L1338.

[42] Shin W, Matsumiya M, Qiu F, Izu N,Murayama N (2002). $(\mathrm{Li}, \mathrm{Na})_{\mathrm{x}} \mathrm{Ni}_{1-\mathrm{x}} \mathrm{O}$ thick-film for thermoelectric gas sensor. $\mathrm{J}$. Ceramic Soc. Jpn.,110: 995-998.

[43] Manna S, Deb AK, Jagannath J, De SK (2008). Synthesis and Room Temperature Ferromagnetism in Fe Doped NiONanorods. J. Phys. Chem.C, 112:10659-10662.

[44] Raja SP, Venkateswaran C (2011).Study of Magnetic and Electrical Properties of NanocrystallineMn Doped NiO. J. Nanosci. Nanotechnol., 11: 2747-2751.

[45] Adler D, Feinleib J (1970). Electrical and optical properties of narrow-band materials. Phys. Rev. B, 2:3112-3134.

[46] Antolini $\mathrm{E}$ (2003). $\mathrm{Li}_{x} \mathrm{Ni}_{1-x} \mathrm{O}(0<x \leq 0.3)$ solid solutions: formation, structure and transport properties. Mater. Chem. Phys., 82: 937-948.

[47] Chen K, Yuan SK, Li PL, Gao F, Liu J, Li GL, Zhao AG, Lu XM, Liu JM, Zhu JS (2007). High permittivity in Zr doped NiO ceramics. J. Appl. Phys., 102: 034103-3.

[48] Chen G-J, Hsiao Y-J, Chang Y-S, Chai Y-L (2009). Structure and high dielectric permittivity of $\mathrm{Li}_{0.01} \mathrm{M}_{0.05} \mathrm{Ni}_{0.94} \mathrm{O}$ ( $\mathrm{M}=\mathrm{V}$ and $\mathrm{W}$ ) Ceramics. J Alloys Comp., 474: 237-240.
[49] Li L, Chen L, Qihe R, Li G (2006). Magnetic crossover of NiOnanocrystals at room temperature. Appl. Phys. Lett., 89:134102-3

[50] Kodama RH, Makhlouf SA, Berkowitz AE (1997). Finite size effects in antiferromagnetic NiO nanoparticles. Phys. Rev. Lett., 79:1393-1396.

[51] Tiwari SD, Rajeev KP (2005). Signatures of spin-glass freezing in NiO nanoparticles.Phys. Rev. B, 72:104433-9.

[52] Tiwari SD, Rajeev KP (2006). Magnetic properties of NiO nanoparticles. Thin Solid Films, 505: 113-117.

[53] Thota S, Kumar J (2007). Sol-gel synthesis and anomalous magnetic behavior of $\mathrm{NiO}$ nanoparticles. J. Phys. Chem. Solids, 68:1951-1964.

[54] Ohno H (1998). Making nonmagnetic semiconductors ferromagnetic. Science, 281: 951-955.

[55] Wolf SA, Awschalom DD, Buhrman RA, Daughton JM, Von Molnar S, Roukes ML, Chtchelkanova AY, Treger DM (2001). Spintronics: A Spin-Based Electronics Vision for the Future. Science, 294:1488-1495.

[56] Janusz TP, Heikes RR, Ohnston JWD (1957). Reinvestigation of Reported Ferromagnetism in $\mathrm{Li}_{x} \mathrm{Ni}_{(1-x)} \mathrm{O}$. J. Chem. Phys., 26: 973-974.

[57] Goodenough JB, Wickam DG, Croft WJ (1958). Some magnetic and crystallographic properties of the system $\mathrm{Li}_{x}^{+} \mathrm{Ni}^{++}{ }_{1-2 x} \mathrm{Ni}^{+++}{ }_{x} \mathrm{O}$. J. Phys. Chem. Solids, 5: 107-116.

[58] Bajpai A, Banerjee A (2000). Superparamagnetism in polycrystalline $\mathrm{Li}_{0.5} \mathrm{Ni}_{0.5} \mathrm{O}$ samples: Low-field susceptibility measurements. Phys. Rev. B, 62: 8996-9004.

[59] Yan W, Weng W, Zhang G, Sun Z, Liu Q, Pan Z, Guo Y, Xu $\mathrm{P}$, Wei S, Zhang Y, Yan S (2008). Structures and magnetic properties of $(\mathrm{Fe}, \mathrm{Li})$-codopedNiO thin films. Appl. Phys. Lett., 92: 052508-3.

[60] Han SJ, Song JW, Yang C-H, Park SH, Park J-H, Jeong YH, Rhie KW (2002). A key to room-temperature ferromagnetism in Fe-doped ZnO: Cu. Appl. Phys. Lett., 81: 4212.

[61] Lin Y-H, Cai J, Nan C-W, Kobayashi M, He J (2006). Electric and magnetic behaviors of $\mathrm{Li}$ and $\mathrm{Co}$ codopedZnO thin film on Si (100) substrate. J. Appl. Phys., 99: 056107.

[62] Bracconi P (1983). Molecular-field treatment of the high temperature susceptibility and Néel temperature of type II antiferromagnetic solid-solutions ${ }_{x} \mathrm{NiO}^{-}{ }_{(1-x)} \mathrm{CoO}$. J. Magn. Magn. Mater., 40: 37-47.

[63] Lin Y-H, Zhan B, Nan C-W, Zhao R, Xu X, Kobayashi M (2011). Ferromagnetism in antiferromagnetic NiO-based thin films. J. Appl. Phys., 110: 043921-4. 